\title{
A systematic review and meta-analysis of radio frequency ablation and routine resection in the treatment of small hepatocellular carcinoma
}

\author{
Yu Li, Weike Xiao, Zhenrong Gao \\ Department of General Surgery, PLA 942 Hospital, Yinchuan, China \\ Contributions: (I) Conception and design: Y Li; (II) Administrative support: None; (III) Provision of study materials or patients: None; (IV) Collection \\ and assembly of data: W Xiao; (V) Data analysis and interpretation: Z Gao; (VI) Manuscript writing: All authors; (VII) Final approval of manuscript: \\ All authors. \\ Correspondence to: Yu Li. Department of General Surgery, PLA 942 Hospital, No. 893 Shengli South Street, Xingqing District, Yinchuan 750004, \\ China. Email: ly15999927412@163.com.
}

Background: This study sought to conduct a meta-analysis of the relevant literature on radiofrequency ablation (RFA) and routine resection in the treatment of small hepatocellular carcinoma (SHCC) in recent years, and to examine the clinical efficacy and safety of different schemes.

Methods: PubMed, The Cochrane Library, Embase, CNKI, Chinese biomedical literature, VIP Chinese journal and the Wanfang Database were used to comprehensively search for relevant papers on clinical control studies of RFA and the routine resection SHCC published between January 2008 and December 2019. The clinical efficacy and safety of different schemes in the treatment of SHCC were compared, including the overall survival rate within 1, 3, and 5 years, and the incidence of complications during treatment. A meta-analysis was undertaken using methods provided by the Cochrane Collaboration and RevMan 5.3 software.

Results: A total of 13 publications of studies were retrieved in which 2,384 patients participated. Of these patients, $1,256(52.68 \%)$ were allocated to the RFA group and 1,128 patients $(47.32 \%)$ to the conventional resection group. The effect size of the 1-year overall survival rate for the two groups was odds ratio (OR): 0.78 [95\% confidence interval (CI), 0.43-1.38]; $\mathrm{Z}$ test: $\mathrm{P}=0.32$. The effect size of the overall survival rate within 3 years was OR: 0.71 (95\% CI, 0.48-1.05); $Z$ test: $\mathrm{P}=0.07$. The difference was not statistically significant. The 5-year overall survival rate of the RFA group and conventional resection group was OR: 0.55 (95\% CI, $0.40-0.72)$. The $\mathrm{OR}$ value fell within the CI, excluding $1 ; \mathrm{Z}$ test: $\mathrm{P}<0.0001$. The difference was statistically significant. The incidence of complications in the RFA group during treatment was lower than that in the conventional resection group (OR: 0.45; 95\% CI, 0.32-0.69). The OR value was within the CI, excluding 1 ; $Z$ test: $\mathrm{P}=0.0002$. The difference was statistically significant.

Conclusions: The short-term effect of RFA in the treatment of SHCC is basically the same as that of routine resection; however, the long-term effect is significantly lower than that of routine resection. RFA has a lower incidence of complications during treatment, and thus better clinical safety.

Keywords: Radiofrequency ablation (RFA); routine resection; small hepatocellular carcinoma (SHCC); efficacy; safety; meta-analysis

Submitted Jan 08, 2021. Accepted for publication Apr 20, 2021.

doi: 10.21037/jgo-21-52

View this article at: http://dx.doi.org/10.21037/jgo-21-52 


\section{Introduction}

Hepatocellular carcinoma (HCC) refers to malignant tumor diseases with lesions in the liver epithelial cells or mesenchymal tissues (1). HCC can be divided into primary or secondary level tumors (1). Primary liver malignant tumors are a type of high-risk malignant tumors. Notably, the incidence of primary liver malignant tumors in China is high. Secondary malignant liver tumors or metastatic liver tumors invade the liver from malignant tumors originating from multiple organs of the whole body, such as liver metastasis of malignant tumors of the stomach, pancreas, colorectum, ovary, uterus, or other organs (2). According to an epidemiological survey, HCC is the second leading cause of death related to malignant tumors worldwide, especially in the Asia-pacific region. Approximately 380,000 patients with HCC die every year in China; a figure that accounts for half of the world's total deaths (3). The main reason for the high clinical mortality rate of HCC is that the strong compensatory function of the human liver results in a lack of obvious symptoms in the early stage of HCC. Patients have often already entered the middle or advanced stages of the disease at the time of diagnoses. International medicine defines HCC as small hepatocellular carcinoma (SHCC), or subclinical HCC or early HCC, for which the maximum diameter of a single cancer nodule is no more than $3 \mathrm{~cm}$ or the sum of the diameters of two nodules is no more than $3 \mathrm{~cm}$. Patients usually have no obvious signs and symptoms of HCC, and the nodules of the tumor body are multi-spherical with distinct boundaries and uniform cut surfaces, and there is no bleeding or necrosis (4). Due to the rapid progression and high recurrence rate of HCC, early detection and the effective treatment of SHCC is key in delaying disease progression and reducing HCC mortality.

Anhydrous ethanol injection and hepatic artery embolization are common palliative methods in the treatment of advanced HCC. Liver transplantation has the highest success rate in the treatment of early HCC (5). According to relevant clinical standards, the maximum diameter of a single tumor must be no more than $5 \mathrm{~cm}$ or the maximum diameter of multiple tumors must be less than $3 \mathrm{~cm}$, and the diameter of tumor body must be no more than $3 \mathrm{~cm}$. HCC without macrovascular invasion and lymph node or extrahepatic metastasis is the most rigorous and best indication for liver transplantation (6). It has been reported that the cure rate of liver transplantation in patients with standard HCC may be as high as $75 \%$, and the recurrence rate within 5 years is less than $10 \%$ (7). However, in clinical practice, liver source is extremely low and treatment costs are high, which causes obvious limitations to the application of liver transplantations. At present, surgical partial hepatectomy is a widely accepted and widely used surgical method; however, it has stringent requirements in terms of patients' body conditions and relatively high trauma. Radiofrequency ablation (RFA) is a therapeutic method that can cure HCC without surgery. Recent studies have shown that this method is relatively effective and safe. There has been controversy regarding the most effective first line treatment modality for the patients who have small solitary hepatocellular carcinoma (HCC) (tumor size of $2-5 \mathrm{~cm}$ ). In this paper, a literature review was undertaken to identify previous studies, and a meta-analysis was conducted to further explore the difference in the effect of RFA and routine resection for SHCC and its application value to provide reliable guidance for clinical practice.

We present the following article in accordance with the PRISMA reporting checklist (available at http://dx.doi. org/10.21037/jgo-21-52).

\section{Methods}

\section{Inclusion criteria}

\section{Type of study}

All patients with SHCC underwent RFA in randomized or non-randomized controlled trials associated with routine resection, regardless of sample size, double-blindness, and assigned concealment. The papers were published between January 2008 and December 2019. The accompanying manuscript does not include studies on humans or animals. Ethics approval could be avoided for this research.

\section{Inclusion criteria}

To be eligible to participate in this study, patients had to meet the following inclusion criteria: (I) Have received a first clinical diagnosis of SHCC consistent with the standard specified that states that "the maximum diameter of a single cancer nodule should not exceed $3 \mathrm{~cm}$; the number of multiple cancer nodules shall not exceed two, and the total maximum diameter shall be less than $3 \mathrm{~cm}$ "; (II) have a Child-Pugh grade of A or B for liver function, no serious chronic disease, and no major organ failure; (III) have completed a first-time treatment; (IV) have undergone treatments limited to RFA and routine resection. Notably, were no limitations in terms of age, sex, race, or nationality.

\section{Interventions}

Participants in the RFA group underwent RFA, while those 


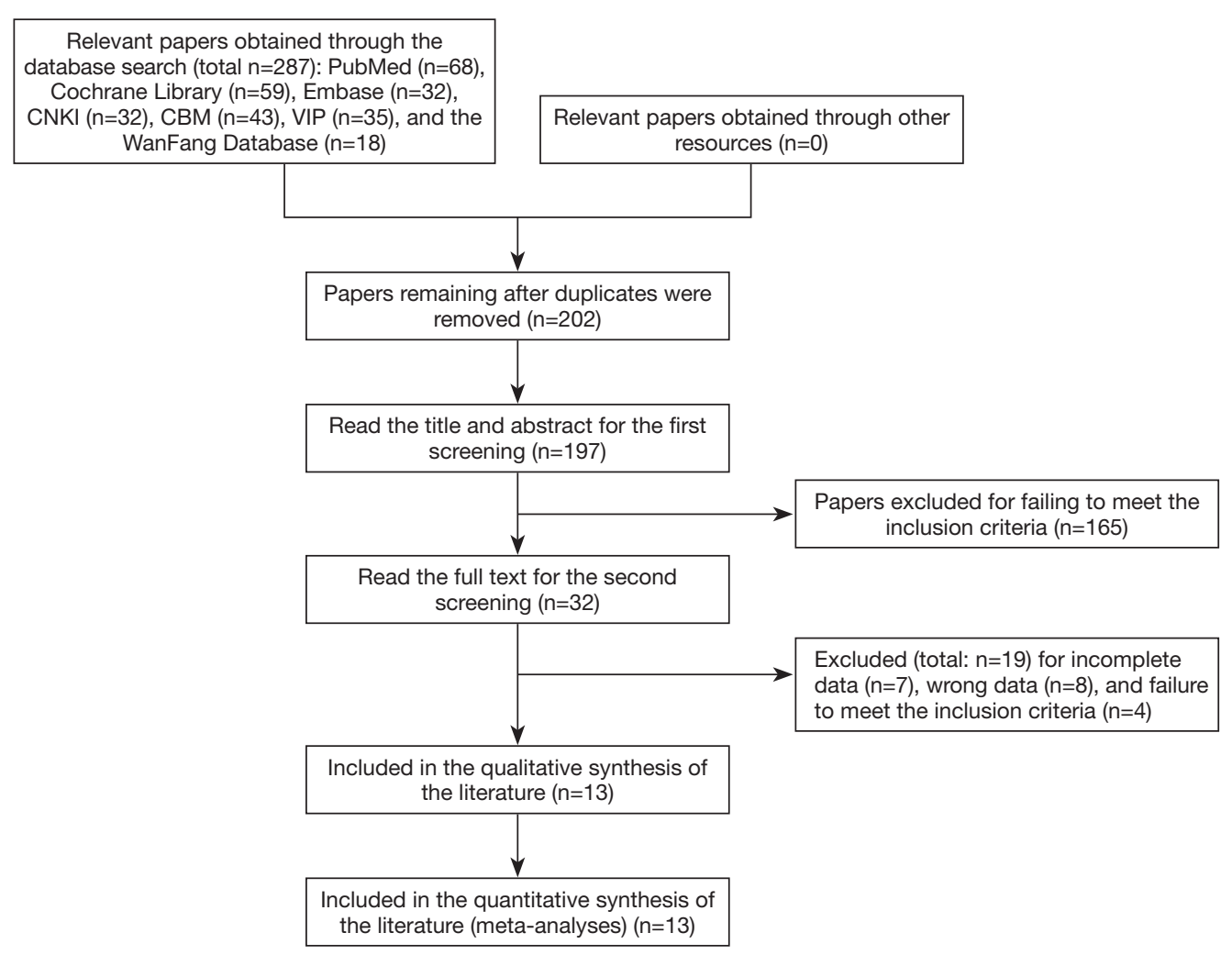

Figure 1 Retrieve and selection guide flow chart.

in the conventional resection group underwent traditional partial hepatectomies.

\section{Outcome indicators}

The outcome indicators for this study were patients' 1-, 3 -, and 5-year overall survival rate, and the incidence of complications during treatment.

\section{Exclusion criteria}

Participants were excluded from the study if: (I) they presented with HCC recurrence or other liver diseases; (II) they had Child-Pugh Grade C liver function; (III) they were not being treated for the first time; (IV) they were being treated with anhydrous ethanol, drugs or other therapeutic programs, such as interventional therapy; and/or (V) their data could not be extracted from the literature.

\section{Retrieval strategy}

In accordance with the systematic evaluation method provided by Cochrane Collaboration, PubMed, The
Cochrane Library, Embase, CNKI, Chinese biomedical literature, VIP Chinese journal, and the Wanfang Database were used to comprehensively search for and identify relevant papers published between January 2008 and December 2019 on clinical control studies of RFA and routine resection in the treatment of SHCC. The retrieval method used subject word retrieval. The subject words included HCC, SHCC, RFA, routine resection. English retrieval terms were linked by "and". Figure 1 shows the retrieve and selection guide flow chart for this study.

\section{Evaluation index}

The evaluation index comprised: (I) a clinical efficacy evaluation; that is, an evaluation of the overall survival rate of SHCC patients in the RFA and conventional resection groups within 1, 3, and 5 years; and (II) a clinical safety assessment of the incidence of complications (including rupture and hemorrhage of HCC, hemorrhage of upper digestive tract, perforation of gastrointestinal tract, ascites, bloody pleural effusion, hepatic encephalopathy, incision infection, and liver and kidney failure) during the implementation of different 
treatment schemes in the two groups.

\section{Evaluation methods}

\section{Literature extraction}

The papers were first independently selected. Data were then extracted and cross-checked by two researchers. To ensure that the quality of the literature extraction was consistent with the analysis results, the PICO (i.e., $\mathrm{P}$ - the object of the study, I-interventions, C-research contrast, $\mathrm{O}$ - the results of the study) principle was followed. Data sorting was used to summarize the data design in relation to the following basic characteristic indicators: the first author, year of publication, grouping design, and quality score.

\section{Literature quality evaluation}

Randomized controlled trials and non-randomized controlled trials were included in the selected literature review, and their quality evaluations were classified according to the Oxford Center for Evidence-Based Medicine's Evidence Evaluation System. Under this system, Grade A refers to randomized controlled clinical trials, cohort studies, all or no conclusive studies, and evidence of clinical decision rules that are consistent and validated in different populations; Grade B refers to prospective cohort studies, retrospective cohort studies, case-control studies, ecological studies, outcome studies, and evidence derived from Grade A evidence that is consistent; Grace C refers to case sequence studies and evidence derived from Grade B evidence; and Grade D refers to studies in which there is a lack of expert opinion for critical evaluations or evidence based on basic medical research. The literature quality grades $\mathrm{A}-\mathrm{D}$ range from excellent to poor. A $\mathrm{P}<0.05$ indicated a statistically significant difference.

\section{Statistical analysis}

A meta-analysis was undertaken using the methods provided by the Cochrane Collaboration and RevMan 5.3 software. Data heterogeneity between the two groups was tested using a Chi-square test. If $\mathrm{I}^{2}<50 \%$, and $\mathrm{P}>0.1$, no heterogeneity was found, or the heterogeneity was small. A fixed-effect model was used for the meta-analysis. If $\mathrm{I}^{2} \geq 50 \%$, and $\mathrm{P} \leq 0.1$, heterogeneity was found. The random-effects model was used for the meta-analysis after the obvious influence of heterogeneity was found and excluded. Binomial variables were described by ratio OR and $95 \%$ confidence intervals (CIs). A descriptive analysis was used for the sensitivity analysis. A $\mathrm{P}<0.05$ and a $\mathrm{P}<0.001$ indicated that the difference was statistically significant.

\section{Results}

\section{Literature retrieval results, data extraction, and basic characteristics}

A total of 13 papers were identified for inclusion in this study, including 5 randomized controlled trials, 8 nonrandomized controlled trials. Of which, 1 was a Grade A publication, 6 were Grade B publications, and 6 were Grade C publications. A total of 2,384 patients were included in the study (of whom 1,539 were male and 845 were female). In relation to Child-Pugh grade, 1,792 cases were Grade A and 449 cases were Grade B (liver function grade was not stated in one publication). In relation to the groups, the RFA group comprised 1,256 patients $(52.68 \%)$ and the conventional resection group comprised 1,128 patients $(47.32 \%)$. The overall and tumor-free 5 -year survival rates of the objects of study were described in all 13 papers within 1,3 , and 5 years. The literature retrieval results, data extraction and basic characteristics are shown in Tables 1 and 2.

\section{Data analysis of results}

\section{Overall survival rates of patients in the RFA and conventional resection groups}

Among the 13 publications included in the meta-analysis, a Chi-square test $\left(\mathrm{P}=0.13, \mathrm{I}^{2}=37 \%\right)$ revealed no significant heterogeneity. The effect size of 1 -year overall survival rate in the two groups was OR, 0.78 (95\% CI, 0.43-1.38); Z test: $\mathrm{P}=0.32$. The difference was not statistically significant (see Figure 2).

Among the 13 publications included in the metaanalysis, a Chi-square test $\left(\mathrm{P}=0.02, \mathrm{I}^{2}=58 \%\right)$ showed heterogeneity. The effect size of the 3 -year overall survival rate for the two groups was OR, 0.71 (95\% CI, 0.48-1.05); $\mathrm{Z}$ test: $\mathrm{P}=0.07$. The difference was not statistically significant (see Figure 3).

Among the 13 publications included in the meta-analysis, 12 described the overall survival rate within 5 years. A Chi-squared test $\left(\mathrm{P}=0.14, \mathrm{I}^{2}=40 \%\right)$ showed no significant heterogeneity. The effect size of the 5 -year overall survival rate for the two groups was OR, 0.55 (95\% CI, 0.40-0.72), and the $\mathrm{OR}$ value was within the $\mathrm{CI}$, excluding $1 ; Z$ test: $\mathrm{P}<0.0001$. The difference was statistically significant (see Figure 4). 
Table 1 Basic information in relation to selected papers

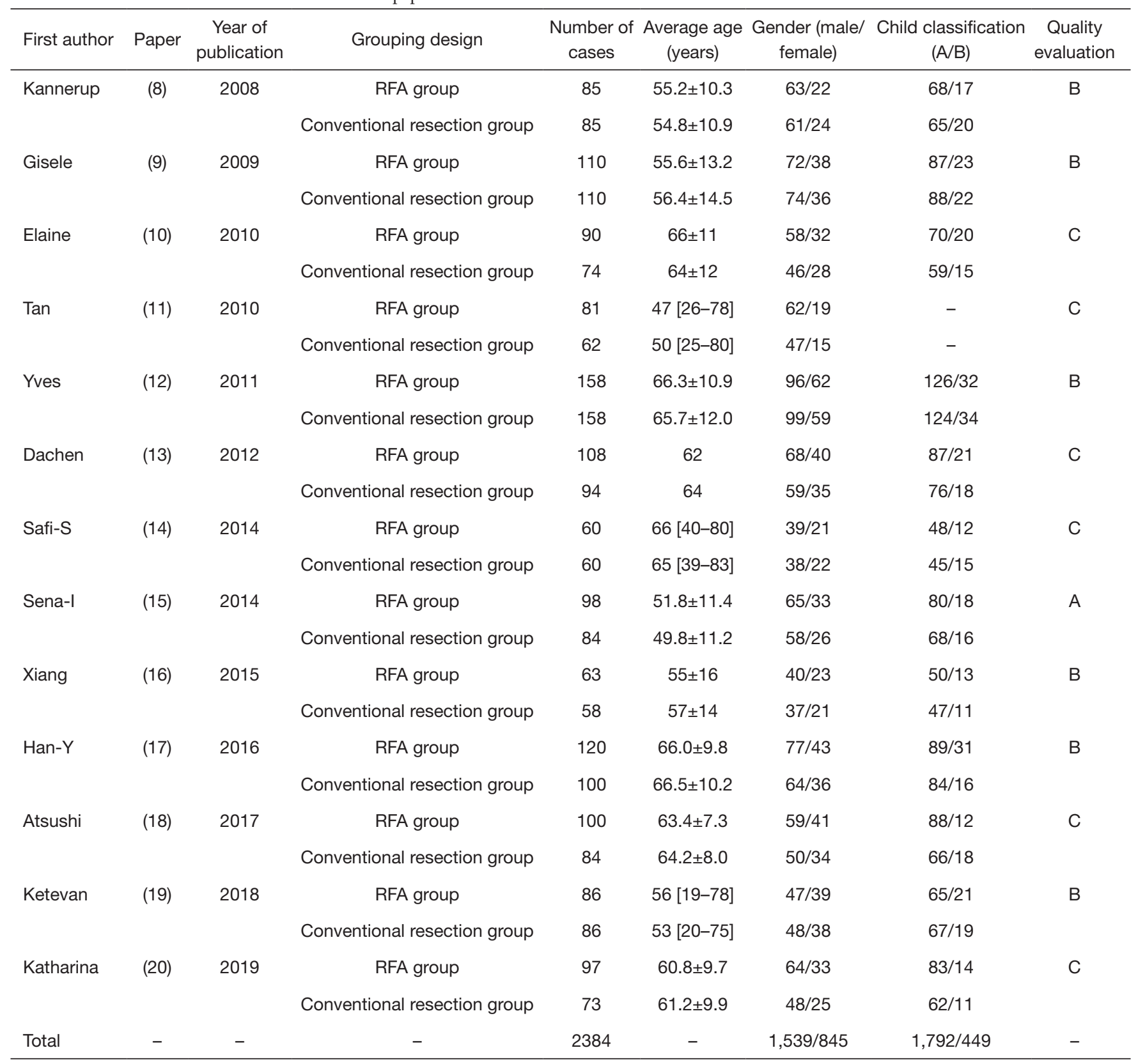

\section{Complication rate between the RFA and conventional resection groups}

Among the 13 publications included in the meta-analysis, a Chi-square test $\left(\mathrm{P}=0.03, \mathrm{I}^{2}=74 \%\right)$ showed significant heterogeneity. The incidence of complications in the RFA group during treatment was lower than that in the conventional resection group (OR, 0.45; 95\% CI, 0.32 0.69 ), and the $\mathrm{OR}$ value was within the $\mathrm{CI}$, excluding $1 ; \mathrm{Z}$ test: $\mathrm{P}=0.0002$. The difference was statistically significant (see Figure 5).

\section{Discussion}

HCC is a malignant tumor disease, and has high clinical morbidity and mortality rates. Its pathogenesis is a complex process that involves multiple factors and steps. Currently, it is generally believed that the occurrence of HCC is mainly influenced by environment and diet (21). The symptoms 
Table 2 Survival of included patients

\begin{tabular}{|c|c|c|c|c|c|c|}
\hline Literature & Grouping design & $\begin{array}{c}\text { Number of } \\
\text { cases }\end{array}$ & \multicolumn{3}{|c|}{ Total survival rate (\%) } & $\begin{array}{c}\text { Complication } \\
\text { rate }(\%)\end{array}$ \\
\hline \multirow[t]{2}{*}{ (8) } & RFA group & 85 & 94.1 & 75.3 & 56.5 & 20.0 \\
\hline & Conventional resection group & 85 & 96.5 & 80.0 & 69.4 & 43.5 \\
\hline (9) & RFA group & 110 & 92.7 & 75.5 & 57.3 & 26.4 \\
\hline \multirow[t]{2}{*}{ (10) } & RFA group & 90 & 93.3 & 74.4 & 57.8 & 25.6 \\
\hline & Conventional resection group & 74 & 94.6 & 79.7 & 73.0 & 32.4 \\
\hline \multirow[t]{2}{*}{ (11) } & RFA group & 81 & 95.1 & 60.5 & 53.1 & 21.0 \\
\hline & Conventional resection group & 62 & 98.4 & 80.6 & 71.0 & 33.9 \\
\hline \multirow[t]{2}{*}{ (13) } & RFA group & 108 & 91.7 & 75.9 & 58.3 & 25.9 \\
\hline & Conventional resection group & 94 & 91.5 & 83.0 & 72.3 & 50.0 \\
\hline \multirow[t]{2}{*}{ (14) } & RFA group & 60 & 93.3 & 76.7 & - & 21.7 \\
\hline & Conventional resection group & 60 & 95.0 & 71.7 & - & 38.3 \\
\hline \multirow[t]{2}{*}{$(15)$} & RFA group & 98 & 91.8 & 75.5 & 56.1 & 24.5 \\
\hline & Conventional resection group & 84 & 94.0 & 83.3 & 71.4 & 38.1 \\
\hline \multirow[t]{2}{*}{ (16) } & RFA group & 63 & 100.0 & 74.6 & 58.7 & 22.2 \\
\hline & Conventional resection group & 58 & 96.6 & 82.8 & 74.1 & 44.8 \\
\hline (19) & Conventional resection group & 86 & 86.0 & 83.7 & 73.3 & 44.2 \\
\hline \multirow[t]{2}{*}{ (20) } & RFA group & 97 & 97.9 & 76.3 & 53.6 & 20.6 \\
\hline & Conventional resection group & 73 & 95.9 & 80.8 & 74.0 & 37.0 \\
\hline
\end{tabular}

of patients with advanced HCC include obvious pain, abdominal distension, poor appetite, weakness and wasting, progressive liver enlargement or a palpable abdominal mass. Some patients may also suffer from low fever, diarrhea, and upper gastrointestinal bleeding. Once HCC rupture and bleeding induces an acute abdomen, the life of a patient is directly threatened (22). At present, the effectiveness of surgical partial hepatectomy and RFA in the treatment of SHCC has been unanimously recognized by the medical community. The Asia-Pacific Association for the Study of the Liver and other associations believe that both these surgical methods can be used as the first-line treatment for HCC with tumors less than $3 \mathrm{~cm}$ in diameter (23). However, with the rapid development of modern medical technology and the rapid progress of minimally invasive technology, an increasing number of doctors and patients prefer treatment plans that result in less trauma and faster recovery. Clinical attention has been directed to and 


\begin{tabular}{|c|c|c|c|c|c|c|c|c|c|c|c|}
\hline \multirow{2}{*}{\multicolumn{2}{|c|}{$\begin{array}{l}\text { Research } \\
\text { literature }\end{array}$}} & \multicolumn{2}{|c|}{ RFA ablation group } & \multicolumn{2}{|c|}{$\begin{array}{c}\text { Conventional excision } \\
\text { group } \\
\end{array}$} & \multirow{3}{*}{$\begin{array}{l}\text { Weight } \\
9.2 \%\end{array}$} & \multirow{3}{*}{$\begin{array}{c}\text { Odds Ratio } \\
\mathrm{y} \text {-H, Fixed, 95\% CI } \\
0.48(0.12-1.87)\end{array}$} & \multirow{2}{*}{\multicolumn{4}{|c|}{$\begin{array}{l}\text { Odds Ratio } \\
\text { Y-H, Fixed, } 95 \% \text { CI }\end{array}$}} \\
\hline & & \multirow{2}{*}{$\begin{array}{c}\text { Events } \\
80\end{array}$} & \multirow{2}{*}{$\begin{array}{c}\text { Total } \\
85\end{array}$} & \multirow{2}{*}{$\begin{array}{c}\text { Events } \\
82\end{array}$} & \multirow{2}{*}{\begin{tabular}{c|} 
Total \\
85
\end{tabular}} & & & & & & \\
\hline Anne-Sofie (8) & 2008 & & & & & & & & - & - & \\
\hline Gisele (9) & 2009 & 102 & 110 & 104 & 110 & 8. $3 \%$ & $0.69(0.33-6.52)$ & & & & \\
\hline Elaine (10) & 2010 & 84 & 90 & 70 & 74 & $9.1 \%$ & $1.21(0.36-1.58)$ & & & - & \\
\hline $\operatorname{Tan}(11)$ & 2010 & 77 & 81 & 61 & 62 & $5.0 \%$ & 1. $77(0.82-5.00)$ & & & & \\
\hline Yves (12) & 2011 & 145 & 158 & 152 & 158 & $21.1 \%$ & $0.12(0.04-0.53)$ & & & & \\
\hline Dachen (13) & 2012 & 99 & 108 & 86 & 94 & 4. 3\% & $6.23(0.37-9.02)$ & & & & \\
\hline Safi-S (14) & 2014 & 56 & 60 & 57 & 60 & $6.0 \%$ & $0.98(0.45-2.06)$ & & & & \\
\hline Sena-I (15) & 2014 & 90 & 98 & 79 & 84 & 3. $1 \%$ & $1.12(0.22-2.18)$ & & & & \\
\hline Xiang (16) & 2015 & 63 & 63 & 56 & 58 & $2.4 \%$ & $0.79(0.53-2.86)$ & & & & \\
\hline Han-Y (17) & 2016 & 113 & 120 & 97 & 100 & $17.2 \%$ & $0.74(0.05-4.01)$ & & & & \\
\hline Atsushi (18) & 2017 & 94 & 100 & 81 & 84 & $11.1 \%$ & $1.28(0.67-5.34)$ & & & & \\
\hline Ketevan (19) & 2018 & 78 & 86 & 74 & 86 & $2.2 \%$ & $1.05(0.39-4.12)$ & & & - & \\
\hline Katharina (20) & 2019 & 95 & 97 & 70 & 73 & $1.0 \%$ & $7.25(0.08-4.32)$ & & & & \\
\hline Total $(95 \%$ & & & 1256 & & 1128 & 100.08 & $0.78(0.43-1.38)$ & & & & \\
\hline Total even & & 1176 & & 1069 & & & & & & & \\
\hline Heteros & genelt & $: \mathrm{Chi}^{2}=14$ & l, $d f=9 \quad(P$ & $=0.13) ;$ & $37 \%$ & & & 0.01 & 0.1 & 10 & 100 \\
\hline Tes & for & overall e & ect: $z=1.2$ & $5(\mathrm{P}=0.32$ & & & & & & & \\
\hline
\end{tabular}

Figure 2 Comparison of the overall survival rate within 1-year between the radiofrequency ablation (RFA) and conventional resection groups.

\begin{tabular}{|c|c|c|c|c|c|c|c|c|c|c|c|}
\hline \multirow{2}{*}{\multicolumn{2}{|c|}{$\begin{array}{l}\text { Research } \\
\text { literature }\end{array}$}} & \multicolumn{2}{|c|}{ RFA ablation group } & \multicolumn{2}{|c|}{$\begin{array}{c}\text { Conventional excision } \\
\text { group } \\
\end{array}$} & \multirow{3}{*}{$\begin{array}{l}\text { Weight } \\
5.4 \%\end{array}$} & \multirow{3}{*}{$\begin{array}{c}\text { Odds Ratio } \\
\text { y-H, Fixed, 95\% CI } \\
1.32(0.58-1.79)\end{array}$} & \multirow{2}{*}{\multicolumn{4}{|c|}{$\begin{array}{l}\text { Odds Ratio } \\
\text { M-H, Fixed, } 95 \% \text { CI }\end{array}$}} \\
\hline & & \multirow{2}{*}{$\frac{\text { Events }}{64}$} & \multirow{2}{*}{$\begin{array}{c}\text { Total } \\
85\end{array}$} & \multirow{2}{*}{$\begin{array}{c}\text { Events } \\
68\end{array}$} & \multirow{2}{*}{$\begin{array}{c}\text { Total } \\
85\end{array}$} & & & & & & \\
\hline Anne-Sofie (8) & 2008 & & & & & & & & & & \\
\hline Gisele (9) & 2009 & 83 & 110 & 87 & 110 & $6.7 \%$ & $0.69(0.37-5.22)$ & & $\longrightarrow$ & - & \\
\hline Elaine (10) & 2010 & 67 & 90 & 59 & 74 & $9.9 \%$ & $0.28(0.48-1.38)$ & & & - & \\
\hline Tan (11) & 2010 & 49 & 81 & 50 & 62 & $5.2 \%$ & $1.75(0.85-5.32)$ & & & & \\
\hline Yves (12) & 2011 & 128 & 158 & 131 & 158 & $14.3 \%$ & $0.54(0.07-0.88)$ & & & & \\
\hline Dachen (13) & 2012 & 82 & 108 & 78 & 94 & $11.2 \%$ & $0.62(0.34-8.12)$ & & & 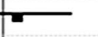 & \\
\hline Safi-S (14) & 2014 & 46 & 60 & 49 & 60 & $9.8 \%$ & $0.98(0.94-2.86)$ & & & & \\
\hline Sena-I (15) & 2014 & 74 & 98 & 70 & 84 & $10.9 \%$ & $0.79(0.70-2.96)$ & & - & - & \\
\hline Xiang (16) & 2015 & 47 & 63 & 48 & 58 & $11.7 \%$ & $0.68(0.45-2.87)$ & & & - & \\
\hline Han-Y (17) & 2016 & 91 & 120 & 82 & 100 & $10.2 \%$ & $0.73(0.09-3.81)$ & & & - & \\
\hline Atsushi (18) & 2017 & 73 & 100 & 71 & 84 & $2.4 \%$ & $3.85(0.52-5.33)$ & & $\longrightarrow$ & - & \\
\hline Ketevan (19) & 2018 & 62 & 86 & 72 & 86 & $1.0 \%$ & $4.02(0.18-4.02)$ & & & & \\
\hline Katharina (20) & 2019 & 74 & 97 & 59 & 73 & $1.3 \%$ & $7.25(0.29-5.36)$ & & & & \\
\hline \multicolumn{2}{|c|}{ Total $(95 \% \mathrm{CI})$} & & 1256 & & 1128 & 100.08 & $0.71(0.48-1.05)$ & & & & \\
\hline \multicolumn{2}{|c|}{ Total events } & 940 & & 924 & & & & & & & \\
\hline \multicolumn{6}{|c|}{ Heterogenelty: $\mathrm{Chi}^{2}=14.38, \mathrm{df}=8(\mathrm{P}=0.02): \mathrm{I}^{2}=58 \%$} & & & \multirow[t]{2}{*}{0.01} & \multirow[t]{2}{*}{0.1} & \multirow[t]{2}{*}{110} & 100 \\
\hline \multicolumn{6}{|c|}{ Test for overall effect: $Z=1.87(P=0.07)$} & & & & & & \\
\hline
\end{tabular}

Figure 3 Comparison of the overall survival rate within 3 years between the radiofrequency ablation (RFA) and conventional resection groups. 


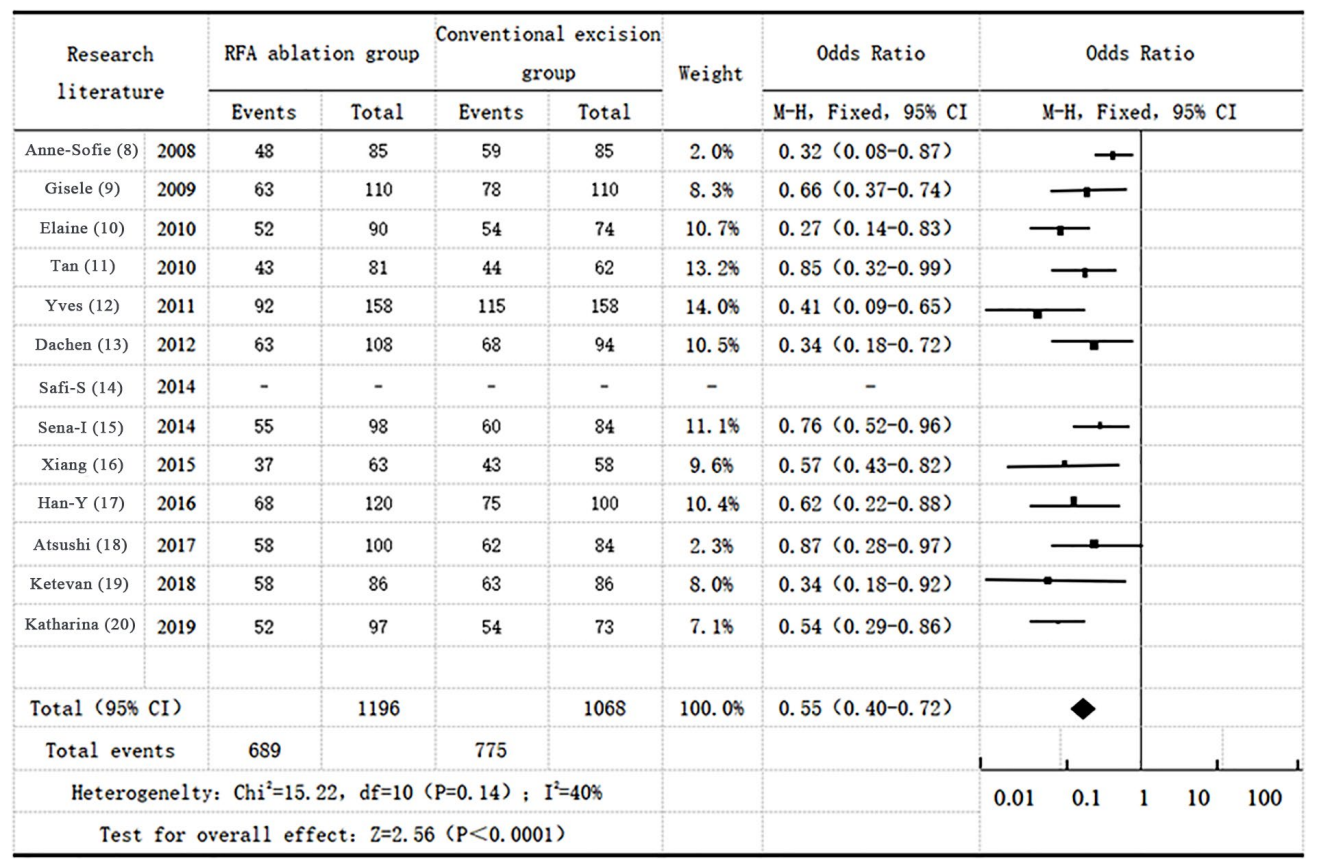

Figure 4 Comparison of the overall survival rate within 5 years between the radiofrequency ablation (RFA) and conventional resection group.

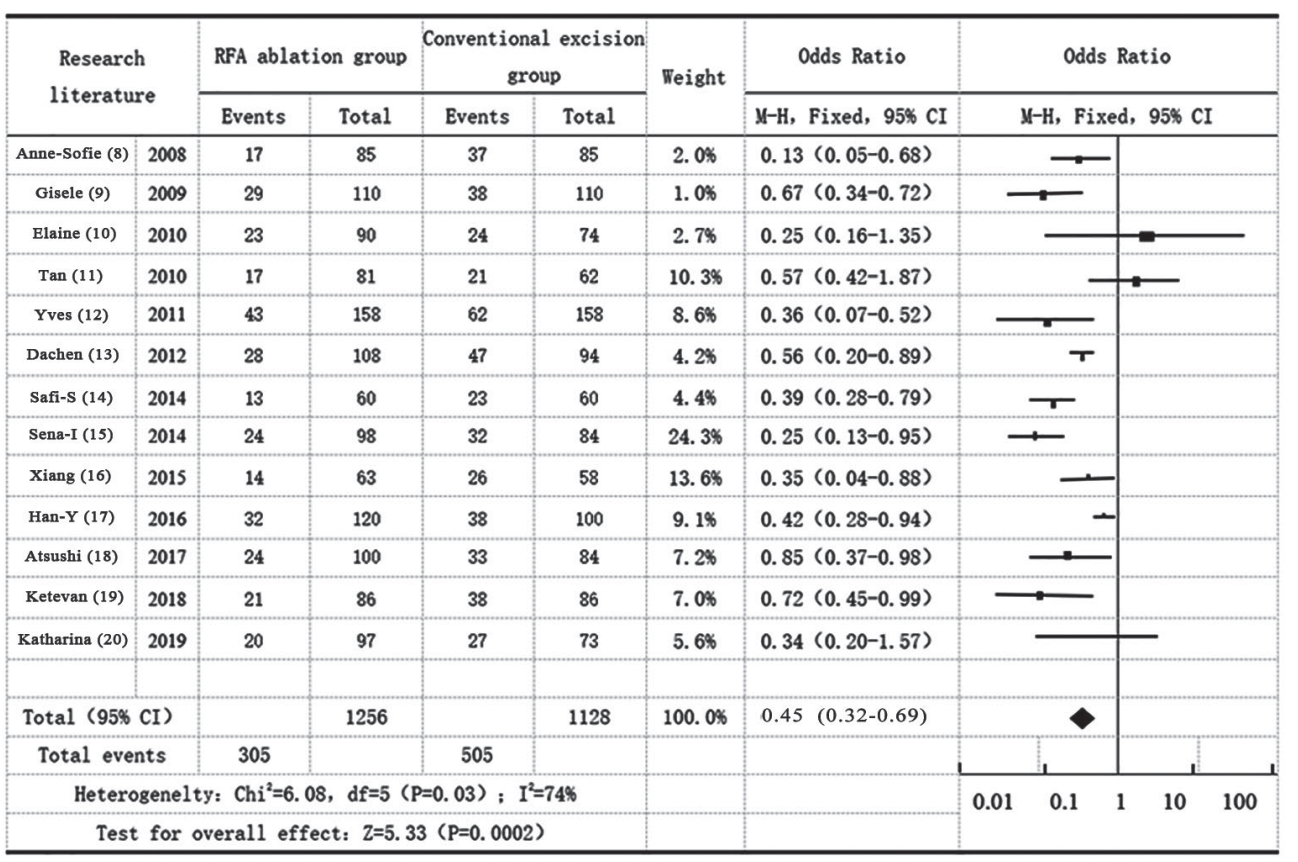

Figure 5 Complication rates for patients in the radiofrequency ablation (RFA) with conventional resection groups. 
research has been actively exploring a treatment method that balances the therapeutic effects and costs.

It is generally recognized in Chinese clinical medicine that if "the largest diameter of a single cancer node in HCC is no more than $3 \mathrm{~cm}$, or the sum of the diameters of two nodules is no more than $3 \mathrm{~cm}$ ", then the HCC is subclinical HCC or early HCC (i.e., SHCC) (24). As the early stage of HCC, SHCC has no obvious clinical symptoms, and its timely detection and treatment can effectively block the progression and spread of HCC, significantly reducing clinical mortality (25). In this paper, a meta-analysis was conducted in which 13 publications from recent years were identified. According to the summary data, RFA and routine resection were used to treat more male patients than female patients with SHCC in clinical practice. Patients' liver function grades were mainly grade A and grade B, which may be related to the common causes of HCC. Patients with hepatitis B and C, viral hepatitis complicated with cirrhosis, and those with a family history of HCC represent multiple HCC prone groups, are mainly affected by environment, diet, virus infection and other multiple factors (26). A history of drinking alcohol can increase the risk of hepatocirrhosis, fatty livers, and other liver-related diseases and also the risk of HCC increases accordingly, therefore, liver function is further impaired.

The comprehensive data showed that there were 1,256 patients in the RFA group, and 1128 patients in the conventional resection group. Of the patients, 1,176 and 1,069 patients survived within 1 year, and the overall survival rate was $93.6 \%$ and $94.8 \%$ for each group, respectively. In the meta-analysis, a Chi-square test $\left(\mathrm{P}=0.13, \mathrm{I}^{2}=37 \%\right)$ indicated that there was no significant heterogeneity between the two groups. The overall survival rate combined with the effect-size results (OR, 0.78; 95\% CI, 0.43-1.38; $\mathrm{Z}$ test: $\mathrm{P}=0.32$ ) indicated that there was no statistically significant difference in the overall survival rate of patients with SHCC within 1 year under the two surgical treatments. Within 3 years, there were 940 and 924 surviving patients in the two groups for which the overall survival rates were $74.8 \%$ and 81.95 for each group, respectively. A Chi-square test $\left(\mathrm{P}=0.02, \mathrm{I}^{2}=58 \%\right)$ showed heterogeneity. However, the effect-size analysis (OR, 0.71; $95 \%$ CI $0.48-1.05 ; Z$ test: $P=0.07$ ) indicated that the difference was also not statistically significant. Thus, both RFA and routine resection have good and similar early effects in the treatment of SHCC, and patients had an overall survival rate of over $74 \%$ within $1-3$ years.

A total of 12 of the 13 publications examined the overall
5 -year survival rate of patients. A Chi-square test $(\mathrm{P}=0.14$, $\mathrm{I}^{2}=40 \%$ ) revealed no significant heterogeneity; however, the effect size of the two combinations was OR, 0.55 (95\% CI, 0.40-0.72). The OR value was within the CI and the CI, excluding 1 . The results for the $Z$ test $(\mathrm{P}<0.0001)$ showed that the difference was statistically significant. The results also showed that routine resection was superior to RFA in the long-term treatment of SHCC. This may be related to the restrictions of the current RFA technique level. The basic principle of operation is that heating current stimulation lesions causes focal cell degeneration necrosis. The operation temperature is influenced by factors such as liver blood circulation, tissue density, and local temperature, which can cause lesions that are difficult to control and can prevent the expected effect from being reached (27). In addition, liver tumor lesions have complex three-dimensional structures, and the cross-distribution of internal blood vessels and branch bile ducts can affect the field of RFA and easily lead to cancer cell residues.

The application safety of the two surgical methods was compared. A Chi-square test $\left(\mathrm{P}=0.03, \mathrm{I}^{2}=74 \%\right)$ showed significant heterogeneity. The complication rate of the RFA group was lower than that of the conventional resection group during treatment (OR, 0.45; 95\% CI, 0.32-0.69. The difference was statistically significant $(Z$ test: $P=0.0002)$, suggesting that the application of RFA is reduces the risk of complications during treatment. The implementation of a conventional partial hepatectomy requires doctors to accurately locate all lesions under direct vision to achieve a complete resection. Thus, this procedure requires a complicate surgical operation, and patients with long intraoperative exposure and large incision trauma are prone to complications such as bleeding, incision infection, and liver failure (28). RFA also requires a complicate surgical operation, but the trauma is much less than that of a routine resection, and patients have better intraoperative safety. Related complications mainly include accidental puncture during operation, thermal radiation injury, gastrointestinal perforation, or tumor metastasis in the chest and abdominal wall. Patients undergoing RFA generally have a short hospital stays and relatively fast postoperative recovery times, which is more advantageous for patients with SHCC, who are old, have poor cardiopulmonary function, or a surgical intolerance.

In summary, RFA can achieve a short-term effect similar to that achieved by the routine resection in the treatment of SHCC, but the long-term effect of this surgical treatment is somewhat poor, and the 5 -year survival rate of patients is 
low. The complication rate of RFA is low and it has a high level of clinical safety.

\section{Acknowledgments}

Funding: None.

\section{Footnote}

Reporting Checklist: The authors have completed the PRISMA reporting checklist. Available at http://dx.doi. org/10.21037/jgo-21-52

Conflicts of Interest: All authors have completed the ICMJE uniform disclosure form (available at http://dx.doi. org/10.21037/jgo-21-52). The authors have no conflicts of interest to declare.

Ethical Statement: The authors are accountable for all aspects of the work in ensuring that questions related to the accuracy or integrity of any part of the work are appropriately investigated and resolved. The accompanying manuscript does not include studies on humans or animals. Ethics approval could be avoided for this research.

Open Access Statement: This is an Open Access article distributed in accordance with the Creative Commons Attribution-NonCommercial-NoDerivs 4.0 International License (CC BY-NC-ND 4.0), which permits the noncommercial replication and distribution of the article with the strict proviso that no changes or edits are made and the original work is properly cited (including links to both the formal publication through the relevant DOI and the license). See: https://creativecommons.org/licenses/by-nc-nd/4.0/.

\section{References}

1. Li YM, Xu SC, Li J, et al. Epithelial-mesenchymal transition markers expressed in circulating tumor cells in hepatocellular carcinoma patients with different stages of disease. Cell Death Dis 2013;4:e831.

2. Xiao YB, Zhang B, Wu YL. Radiofrequency ablation versus hepatic resection for breast cancer liver metastasis: a systematic review and meta-analysis. J Zhejiang Univ Sci B 2018;19:829-43.

3. Liu W, Yang Z, Zou R, et al. Resection vs Ablation for Multifocal Hepatocellular Carcinomas meeting the Barcelona-Clinic Liver Cancer A Classification:
A Propensity Score Matching Study. J Cancer 2019;10:2857-67.

4. Chong CC, Chan AW, Wong J, et al. Albumin-bilirubin grade predicts the outcomes of liver resection versus radiofrequency ablation for very early/early stage of hepatocellular carcinoma. Surgeon 2018;16:163-70.

5. Fukuda Y, Asaoka T, Eguchi H, et al. A Case of Repeated Surgical Resections for Tumor Seeding of Hepatocellular Carcinoma after Radiofrequency Ablation. Gan To Kagaku Ryoho 2018;45:342-4.

6. Mergental H, Porte RJ. Liver transplantation for unresectable hepatocellular carcinoma in patients without liver cirrhosis. Transpl Int 2010;23:662-7.

7. Hirooka M, Hiraoka A, Ochi H, et al. Transcatheter Arterial Chemoembolization With or Without Radiofrequency Ablation: Outcomes in Patients With Barcelona Clinic Liver Cancer Stage B Hepatocellular Carcinoma. AJR Am J Roentgenol 2018;210:891-8.

8. Kannerup AS, Nielsen DT, Sørensen SM, et al. Combined liver resection and radiofrequency ablation for colorectal liver metastases. Ugeskr Laeger 2008;170:1338-41.

9. N'Kontchou G, Mahamoudi A, Aout M, et al. Radiofrequency ablation of hepatocellular carcinoma: long-term results and prognostic factors in 235 Western patients with cirrhosis. Hepatology 2009;50:1475-83.

10. Leung EY, Roxburgh CS, Leen E, et al. Combined resection and radiofrequency ablation for bilobar colorectal cancer liver metastases. Hepatogastroenterology 2010;57:41-6.

11. Cheung TT, Ng KK, Chok KS, et al. Combined resection and radiofrequency ablation for multifocal hepatocellular carcinoma: prognosis and outcomes. World J Gastroenterol 2010;16:3056-62.

12. Dittmar Y, Altendorf-Hofmann A, Rauchfuss F, et al. Resection of liver metastases is beneficial in patients with gastric cancer: report on 15 cases and review of literature. Gastric Cancer 2012;15:131-6.

13. Zhou DC, Geng XP, Zhu LX, et al. Percutaneous radiofrequency ablation versus hepatic resection for small hepatocellular carcinoma: a meta analysis. Zhonghua Wai Ke Za Zhi 2011;49:1132-6.

14. Safi S, Winkel JOD, Huber P, et al. Outcomes following sublobar resection, radiofrequency ablation and stereotactic body radiation therapy for stage I non-small cell lung cancer: a retrospective analysis. Interactive Cardiovascular \& Thoracic Surgery 2014;18:S17.

15. Iwamura $S$, Iida $T$, Terajima $H$, et al. Hepatic resection for local recurrence after radiofrequency ablation therapy 
for colorectal liver metastases. Gan To Kagaku Ryoho 2014;41:2062-4.

16. Bu X, Ge Z, Ma J, et al. Long-term efficacy of radiofrequency ablation compared to surgical resection for the treatment of small hepatocellular carcinoma. J BUON 2015;20:548-54.

17. Han Y, Yan D, Xu F, et al. Radiofrequency Ablation versus Liver Resection for Colorectal Cancer Liver Metastasis: An Updated Systematic Review and Meta-analysis. Chin Med J (Engl) 2016;129:2983-90.

18. Hiraoka A, Kumada T, Michitaka K, et al. Clinical features of hemodialysis patients treated for hepatocellular carcinoma: Comparison between resection and radiofrequency ablation. Mol Clin Oncol 2017;6:455-61.

19. Mazmishvili K, Jayant K, Janikashvili N, et al. Study to evaluate the immunomodulatory effects of radiofrequency ablation compared to surgical resection for liver cancer. J Cancer 2018;9:3187-95.

20. Schoene K, Sepehri Shamloo A, Sommer P, et al. Natural course of acquired pulmonary vein stenosis after radiofrequency ablation for atrial fibrillation-Is routine follow-up imaging indicated or not? J Cardiovasc Electrophysiol 2019;30:1786-91.

21. Sun WC, Chen IS, Liang HL, et al. Comparison of repeated surgical resection and radiofrequency ablation for small recurrent hepatocellular carcinoma after primary resection. Oncotarget 2017;8:104571-81.

22. Guo YL, Tong ZH, Xu X, et al. Colorectal resection combined with simultaneous radiofrequency ablation in the treatment of synchronous colorectal liver metastases: a retrospective analysis. Zhonghua Yi Xue Za Zhi 2017;97:925-8.

23. Changyong E, Wang D, Yu Y, et al. Efficacy comparison of radiofrequency ablation and hepatic resection for hepatocellular carcinoma: A meta-analysis. J Cancer Res Ther 2017;13:625-30.

24. Sheng S, Sun B, Zheng J, et al. Transcatheter hepatic arterial chemoembolization combined with CT guided radiofrequency ablation for treatment of primary Hepatocellular carcinoma in caudate lobe. Journal of Interventional Radiology (China) 2017;14:391-5.

25. Hollender P, Kuo L, Chen V, et al. Scanned 3-D Intracardiac ARFI and SWEI for Imaging RadioFrequency Ablation Lesions. IEEE Trans Ultrason Ferroelectr Freq Control 2017;64:1034-44.

26. Nagasu S, Okuda K, Kuromatsu R, et al. Surgically treated diaphragmatic perforation after radiofrequency ablation for hepatocellular carcinoma. World J Gastrointest Surg 2017;9:281-7.

27. Hiraoka A, Kumada T, Michitaka K, et al. Clinical features of hemodialysis patients treated for hepatocellular carcinoma: Comparison between resection and radiofrequency ablation. Mol Clin Oncol 2017;6:455-61.

28. Desai M, Saligram S, Gupta N, et al. Efficacy and safety outcomes of multimodal endoscopic eradication therapy in Barrett's esophagus-related neoplasia: a systematic review and pooled analysis. Gastrointest Endosc 2017;85:482-95.

(English Language Editor: L. Huleatt)
Cite this article as: $\mathrm{Li} \mathrm{Y,} \mathrm{Xiao} \mathrm{W,} \mathrm{Gao} \mathrm{Z.} \mathrm{A} \mathrm{systematic} \mathrm{review}$ and meta-analysis of radio frequency ablation and routine resection in the treatment of small hepatocellular carcinoma. J Gastrointest Oncol 2021;12(2):770-780. doi: 10.21037/jgo-21-52 